\title{
Inhibition Effect of 1-Butyl-4-Methylpyridinium Tetrafluoroborate on the Corrosion of Copper in Phosphate Solutions
}

\author{
M. Scendo and J. Uznanska \\ Institute of Chemistry, UJK Kielce, Swietokrzyska Street 15G, 25406 Kielce, Poland \\ Correspondence should be addressed to M. Scendo, scendo@ujk.edu.pl \\ Received 19 November 2010; Accepted 1 February 2011 \\ Academic Editor: Flavio Deflorian
}

Copyright ( $) 2011$ M. Scendo and J. Uznanska. This is an open access article distributed under the Creative Commons Attribution License, which permits unrestricted use, distribution, and reproduction in any medium, provided the original work is properly cited.

The influence of the concentration of 1-Butyl-4-methylpyridinium tetrafluoroborate $\left(4 \mathrm{MBPBF}_{4}\right)$ as ionic liquid (IL) on the corrosion of copper in $0.5 \mathrm{M} \mathrm{PO}_{4}^{3-}$ solutions of $\mathrm{pH} 2$ and 4 was studied. The research involved electrochemical polarization method, and scanning electron microscopy (SEM) technique. The results obtained showed that the inhibition efficiency of corrosion of copper increases with an increase in the concentration of $4 \mathrm{MBPBF}_{4}$ but decreases with increasing temperature. The thermodynamic functions of corrosion analysis and adsorptive behavior of $4 \mathrm{MBPBF}_{4}$ were carried out. During the test, the adsorption of the inhibitor on the copper surface in the phosphate solutions was found to obey the Langmuir adsorption isotherm and had a physical mechanism.

\section{Introduction}

Copper is used as a construction metal in the central heating installations, car industry, energetics, oil refineries, sugar factories, marine environment, to name only a few of its various applications. This extensive use of copper is due to its mechanical and electric properties as well as the behaviour of its passivation layer. Acidic solutions are widely used in various industries for the cleaning of copper. The behaviour of copper in acidic media is extensively investigated, and several ideas have been presented for the dissolution process $[1,2]$. To avoid the base metal attack and to ensure the removal of corrosion products/scales alone, inhibitors are extensively used. The most well-known acid inhibitors are organic compounds containing nitrogen, phosphor, sulfur, and oxygen atoms. The surfactant inhibitors have many advantages such as high inhibition efficiency (IE), low price, low toxicity, and easy production [3-5]. The interactions between the inhibitor molecules and the metal surfaces should by all means be explained and understood in detail. In examining of these interactions, theoretical approaches applied can be very useful [6-10]. Many N-heterocyclic compounds have been used for the corrosion inhibition of metals, such as imidazoline [11], triazole [12-14], tetrazole [15], pyrrole [16], pyridine [17], pyrazole and bipyrazole [18, 19], pyrimidine [20], pyridazine [21], and some derivatives. Some heterocyclic compounds containing a mercapto group have been developed as copper corrosion inhibitors. These compounds include: 2-mercaptobenzothiazole [22], 2,4dimercaptopyrimidine [23], 2-amino-5-mercaptothiadzole, 2-mercaptothiazoline [24], potassium ethyl xanthate [2528] and indole and derivatives [29]. Among the numerous organic compounds tested and industrially applied as corrosion inhibitors, nontoxic ones are far more strategic now than in the recent past. These compounds include such amino acids [30-32] and derivatives as cysteine [33].

In the past two decades, the research in the field of green corrosion inhibitors has been addressed towards the goal of using cheap effective molecules at low or zero environmental impact. These compounds include purine and adenine, which have been tested for copper corrosion in chloride $[34,35]$, sulfate [36], and nitrate solutions [37]. 
Ionic liquids (ILs) are molten salts with melting points at/or below ambient temperature, which are composed of organic cations and various anions. Configuration of ILs consists of an amphiphilic group with a long chain, hydrophobic tail, and a hydrophilic polar head. Usually, ILs have nitrogen, sulphur, and phosphorus as the central atoms of cations, such as imidazolium, pyrrolidinium, quaternay ammonium, pyridinium, piperidinium, sulfonium and quaternary phosphonium. Currently, funtionalized IL is a very noticeable topic in the field of IL research. Introducing different functional groups into cations provides a great deal of ILs with new structures that can markedly change the physicochemical properties of ILs, and it also affords more choices for applications of ILs in electrochemical devices.

Imidazolium compounds are reported to show corrosion resistant behavior on mild steel [38], copper [39, 40], and aluminium [41]. It was found that the action of such inhibitors depends on the specific interaction between the functional groups and the metal surface, due to the presence of the $-\mathrm{C}=\mathrm{N}$ - group and electronegative nitrogen in the molecule. Ionic liquids and different types of surfactans base inhibitors are well known to have a high activity in acid medium $[42,43]$ and therefore are used in an oil field to minimize carbon-dioxide-induced corrosion [44, 45]. Among many kinds of functionalized ionic liquids ether-functionalized ILs have been investigated intensively, and ether groups have been successfully introduced in to imidazolium cations [46-52].

However, no substantial information is available on pyridinium ionic liquids being used as corrosion inhibitors of copper.

The present work describes a study of the corrosion of copper in $0.5 \mathrm{M} \mathrm{PO}_{4}^{3-}$ solutions of $\mathrm{pH} 2$ and 4 without and with different concentrations of 1-Butyl-4methylpyridinium tetrafluoroborate $\left(4 \mathrm{MBPBF}_{4}\right)$, based on copper stationary disc electrode voltammetry measurements and scanning electron microscope. Moreover, the thermodynamic functions were appointed for the adsorption process and to gain more information about the mode of adsorption of the inhibitor on the surface of copper.

\section{Experimental Methods}

2.1. Solutions. 1-Butyl-4-methylpyridinium tetrafluoroborate $\left(4 \mathrm{MBPBF}_{4}\right)(>99.8 \%)$ was purchased from Fluka. The molecular structures of compound are shown in Figure 1. It is worth to notice that $4 \mathrm{MBPBF}_{4}$ is not flat molecule. The $4 \mathrm{MBPBF}_{4}$ is stable in air, water, and in majority organic solvents. However, this compound is well enough solvable in water. All the solutions were prepared using analytical grade reagent and triple distilled water (resistivity $13 \mathrm{M} \Omega \mathrm{cm}$ ). The $4 \mathrm{MBPBF}_{4}$ was dissolved at concentrations in the range of $1.0-50.0 \mathrm{mM}$ in $0.5 \mathrm{M} \mathrm{PO}_{4}^{3-}$ solutions of $\mathrm{pH} 2$ and 4. During the measurements, the solution was not stirred or deaerated.

2.2. Electrodes and Apparatus. The working electrode was a home-made stationary disk electrode (SDE) of Specpure copper (Johnson Matthey Chemicals Ltd.) with $r=0.240 \mathrm{~cm}$

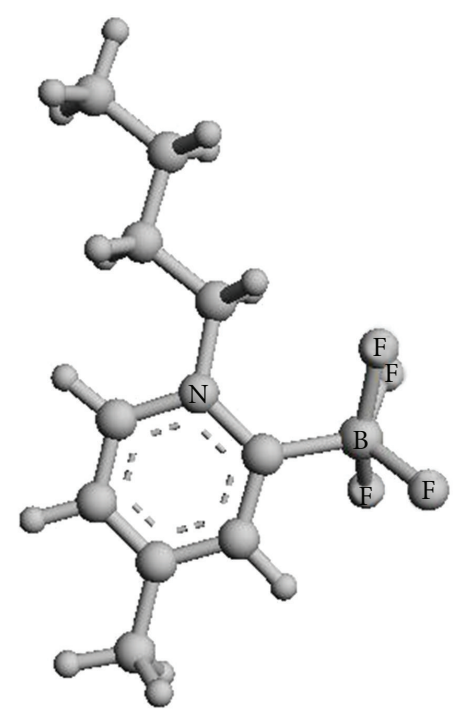

FIgURE 1: Molecular structure ionic liquid: 1-Butyl-4methylpyridinium tetrafluoroborate $\left(4 \mathrm{MBPBF}_{4}\right)$.

and $A=0.181 \mathrm{~cm}^{2}$. Prior to each experiment the working electrode was mechanically polished to mirror gloss by using 1000 and 2000-grade emery papers. Then the electrode was washed several times interchangeably with bidistilled water and ethanol. Finally, SDE was dried using a stream of air. Such pretreatment of the disk was repeated after each voltammetric measurement. Other details were published in [53-56]. All the surface-area-dependant values are normalized with respect to the geometric surface area of the working electrode.

Electrode potentials were measured and reported against the external saturated calomel electrode with $\mathrm{NaCl}$ solution ( $\mathrm{SCE}(\mathrm{NaCl}))$ coupled with a fine Luggin capillary. To minimize the ohmic contribution, the capillary was kept close to the working electrode. A platinum (purity 99.99\%) wire was used as an auxiliary electrode. Auxiliary electrode was individually isolated from the test solution by a glass frit.

All voltammetric experiments were performed using a Model EA9C electrochemical analyzer, controlled via Pentium computer using the software Eagraph V. 4.0.

2.3. Scanning Electron Microscope. A scanning electron microscope (SEM) PHILIPS XL 30 was used to study the morphology of the copper surface in the absence and presence of the inhibitor. Samples were attached on top of an aluminum stopper by means of $3 \mathrm{M}$ carbon conductive adhesive tape (SPI).

2.4. Potentiodynamic Polarization Measurements. Electrochemical experiments were carried out in a classical threeelectrode glass cell. The cell was open to air. The degreased SDE was quickly inserted into the solution and immediately cathodically polarized at $-1100 \mathrm{mV}(\mathrm{SCE}(\mathrm{NaCl}))$ for $3 \mathrm{~min}$ to reduce any oxide on the copper surface. The polarization curves were obtained using the linear potential sweep (LSV) 


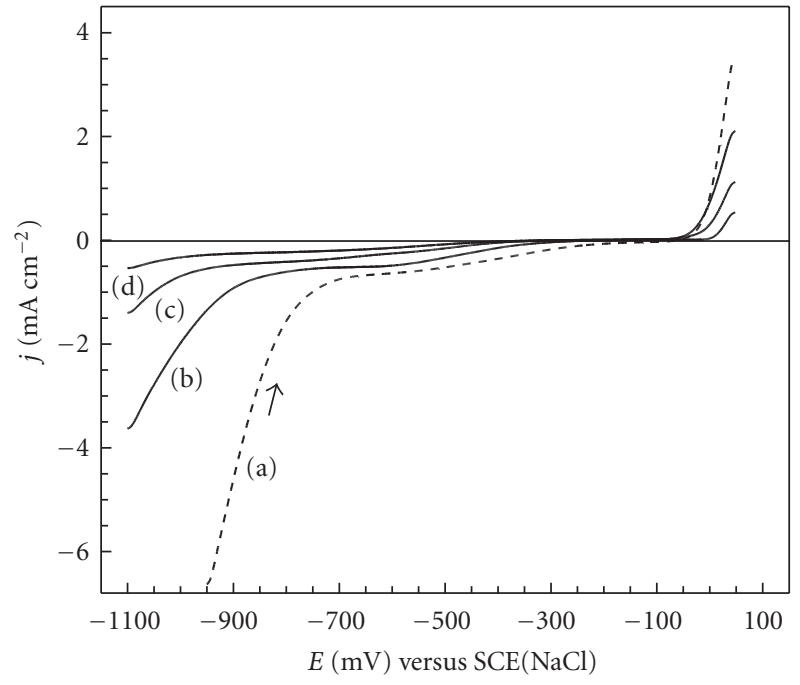

FIGURE 2: Some chosen polarization curves of the copper electrode in $0.5 \mathrm{M} \mathrm{PO}_{4}^{3-}$ solutions containing different concentrations of 1Butyl-4-methylpyridinium tetrafluoroborate: (a) 0, (b) 1.0, (c) 10.0, and (d) $50.0 \mathrm{mM}, \mathrm{pH} 4, \mathrm{dE} / \mathrm{dt} 1 \mathrm{mV} \mathrm{s}^{-1}$.

technique. The scan started from the cathodic $(-1100 \mathrm{mV})$ to the anodic direction with the scan rate of $1 \mathrm{mV} \mathrm{s}^{-1}$. Electrochemical experiments were repeated many times, and the average values of the current were used.

All experiments were carried out using an air thermostat with the forced air circulation.

\section{Experimental Results and Discussion}

3.1. Polarization Behaviour of Copper. The effect of 1-Butyl4-methylpyridinium tetrafluoroborate $\left(4 \mathrm{MBPBF}_{4}\right)$ on the corrosion reactions of copper was determined by polarization measurements at $20^{\circ} \mathrm{C}$. Figure 2 shows example of polarization curves for the copper electrode in $0.5 \mathrm{M} \mathrm{PO}_{4}^{3-}$ solutions of $\mathrm{pH} 4$ without and with different concentrations of $4 \mathrm{MBPBF}_{4}$. Similar curves were recorded for solution of $\mathrm{pH}$ 2. It is clear that the presence of different concentrations of the inhibitor decreases the current densities and reduces both of the cathodic and anodic current densities in comparison to those recorded in the additive-free solution. However, in case of more acid solutions $(\mathrm{pH} 2)$ were observed smaller changes in the cathodic and anodic current densities. The decrease in current densities could be attributed to the decrease in the phosphate ions attack on the copper surface due to the adsorption of the inhibitor molecules at the copper/solution interface.

3.1.1. Corrosion Parameters. The corrosion kinetic parameters were calculated on the basis of cathodic and anodic potential versus current characteristics in the Tafel potential region (Figure 3$)$. The corrosion parameters such as corrosion potential $\left(E_{\text {corr }}\right)$, corrosion current density $\left(j_{\text {corr }}\right)$, and cathodic $\left(b_{c}\right)$ and anodic $\left(b_{a}\right)$ Tafel slope are listed in Table 1. It is worth noticing that addition of the $4 \mathrm{MBPBF}_{4}$

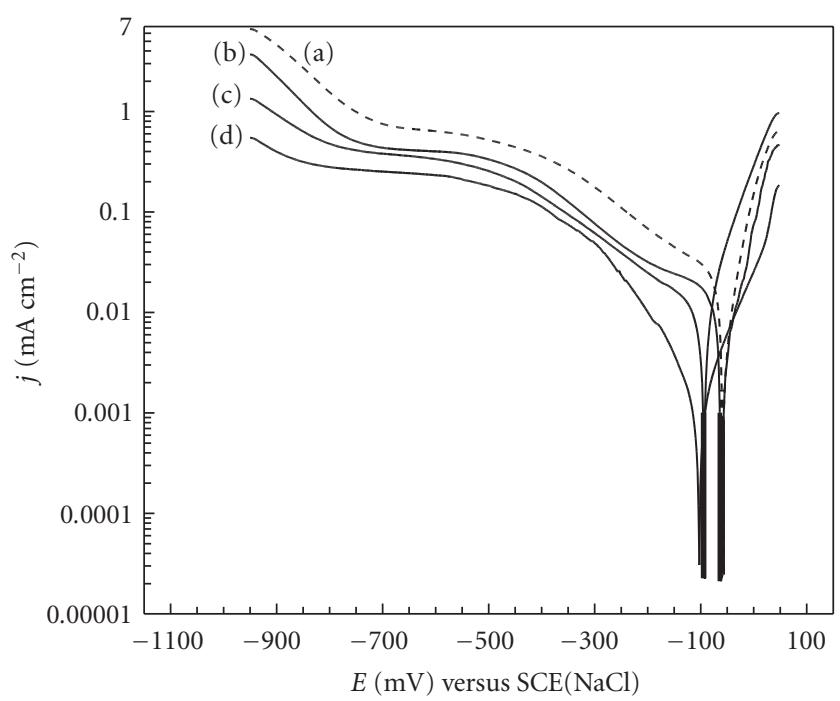

Figure 3: Some chosen Tafel plots of the copper electrode in $0.5 \mathrm{M}$ $\mathrm{PO}_{4}^{3-}$ solutions containing different concentrations of 1-Butyl-4methylpyridinium tetrafluoroborate: (a) 0, (b) 1.0, (c) 10.0 and (d) $50.0 \mathrm{mM}, \mathrm{pH} 2, \mathrm{dE} / \mathrm{dt} 1 \mathrm{mV} \mathrm{s}^{-1}$.

causes more negative shift in corrosion potential values independently from $\mathrm{pH}$ solutions. Hence small changes in potentials can be a result of the competition of the cathodic and the anodic inhibiting reactions.

The corrosion current density (Table 1) decreased when the concentrations of 1-Butyl-4-methylpyridinium tetrafluoroborate were increased for both solutions of $\mathrm{pH} 2$ and 4. This indicates the inhibiting effect of $4 \mathrm{MBPBF}_{4}$ on corrosion of copper. The decrease in cathodic $\left(b_{c}\right)$ and anodic $\left(b_{a}\right)$ or the increase in $\left(b_{a}\right)$ only in case of solutions of pH 4 Tafel slopes (Table 1) indicated that the 1-Butyl-4methylpyridinium tetrafluoroborate molecules are adsorbed on both the anodic and cathodic sites resulting in an inhibition of both anodic dissolution of copper and cathodic reduction reactions. Moreover, these inhibitors cause small change in the cathodic and anodic Tafel slopes, indicating that $4 \mathrm{MBPBF}_{4}$ is first adsorbed onto copper surface and therefore impedes the reaction by merely blocking the reaction sites of copper surface without affecting the cathodic and anodic reaction mechanism [57].

3.1.2. Polarization Resistance. The polarization resistance $\left(R_{p}\right)$ values are related to the corrosion current density $\left(j_{\text {corr }}\right)$, which can be calculated from the equation:

$$
R_{p}=\left[\frac{b_{a} b_{c}}{2.303\left(b_{a}+b_{c}\right)}\right] \times\left[\frac{1}{j_{\text {corr }}}\right] .
$$

The $R_{p}$ values listed in Table 1 are used to estimate the corrosion inhibition effect of the inhibitor. The addition of 1-Butyl-4-methylpyridinium tetrafluoroborate to the phosphate solutions produced higher $R_{p}$ values than the blank solution indicating the formation of a protective layer on the electrode surface. Hence, the polarization resistance values increase with an increase in the concentration of $4 \mathrm{MBPBF}_{4}$ 
TABLE 1: Corrosion parameters and polarization resistance of copper electrode in $0.5 \mathrm{M} \mathrm{PO}_{4}^{3-}$ solutions in the absence or presence of different concentrations of 1-Butyl-4-methylpyridinium tetrafluoroborate $\left(4 \mathrm{MBPBF}_{4}\right)$ of $\mathrm{pH} 2$ and 4 at $20^{\circ} \mathrm{C}$.

\begin{tabular}{|c|c|c|c|c|c|c|c|}
\hline Inhibitor & $\mathrm{pH}$ & $\begin{array}{l}\text { Concentration } \\
\text { inhibitor }(\mathrm{mM})\end{array}$ & $-E_{\text {corr }}(\mathrm{mV})$ & $j_{\text {corr }}\left(\mu \mathrm{A} \mathrm{cm}^{-2}\right)$ & $-b_{c}\left(\mathrm{mV} \mathrm{dec}{ }^{-1}\right)$ & $b_{a}\left(\mathrm{mV} \mathrm{dec}^{-1}\right)$ & $R_{P}\left(\Omega \mathrm{cm}^{2}\right)$ \\
\hline Blank & \multirow{6}{*}{2} & 0.0 & 60 & 29.0 & 300 & 75 & 898 \\
\hline \multirow{5}{*}{$4 \mathrm{MBPBF}_{4}$} & & 1.0 & 64 & 16.0 & 280 & 70 & 1519 \\
\hline & & 5.0 & 79 & 13.2 & 277 & 67 & 1846 \\
\hline & & 10.0 & 94 & 10.5 & 275 & 65 & 2174 \\
\hline & & 25.0 & 99 & 6.5 & 228 & 63 & 5158 \\
\hline & & 50.0 & 104 & 2.4 & 180 & 60 & 8141 \\
\hline \multirow[t]{3}{*}{ Blank } & & 0.0 & 60 & 20.0 & 240 & 160 & 2084 \\
\hline & & 1.0 & 200 & 10.0 & 175 & 190 & 3955 \\
\hline & 4 & 5.0 & 240 & 8.0 & 148 & 291 & 5987 \\
\hline \multirow[t]{3}{*}{$4 \mathrm{MBPBF}_{4}$} & & 10.0 & 278 & 5.0 & 120 & 400 & 8016 \\
\hline & & 25.0 & 273 & 3.4 & 115 & 410 & 13478 \\
\hline & & 50.0 & 268 & 1.2 & 110 & 420 & 27824 \\
\hline
\end{tabular}

for both solutions of $\mathrm{pH} 2$ and 4 . It seems that protective layer created on surface of copper is the most tight in of less acid solution about the largest concentration of 1-Butyl-4methylpyridinium tetrafluoroborate.

3.1.3. Inhibition Efficiency. Inhibition efficiency (IE) can also be calculated from polarization tests by using the following equation $[58,59]$ :

$$
I E(\%)=\left(\frac{j_{o}-j_{\text {corr }}}{j_{o}}\right) \times 100,
$$

where $j_{o}$ and $j_{\text {corr }}$ are the corrosion current densities in the absence and presence of inhibitor, respectively.

The inhibition efficiency depends on both the nature and the concentration of the investigated compounds. The calculated inhibition efficiencies are presented in Figure 4. In the presence of 1-Butyl-4-methylpyridinium tetrafluoroborate solution of $\mathrm{pH} 2$ and 4, the inhibition efficiency increases with an increase in the concentration of inhibitor. This confirms the inhibiting character of 1-Butyl4-methylpyridinium tetrafluoroborate. However, IE is higher in case of solution of $\mathrm{pH} 4$ than 2 . It is obvious that in the presence of 1-Butyl-4-methylpyridinium tetrafluoroborate solution of $\mathrm{pH} 2$ the film on copper does not cover tightly the surface and hence does not protect it prior to corrosion of $\mathrm{Cu}$ in an adequate degree.

3.1.4. Corrosion Rate. The corrosion current density $\left(j_{\text {corr }}\right)$ was converted into the corrosion rate $\left(k_{r}\right)$ by using the expression [60]:

$$
k_{r}\left(\frac{\mathrm{mm}}{\text { year }}\right)=3.268 \times 10^{-3}\left(\frac{j_{\text {corr }} \times M_{\mathrm{Cu}}}{n \rho}\right),
$$

where $M_{\mathrm{Cu}}$ is the molecular weight of copper, $n$ is the number of electrons transferred in the corrosion reaction, and $\rho$ is the density of $\mathrm{Cu}\left(\mathrm{g} \mathrm{cm}^{-3}\right)$.

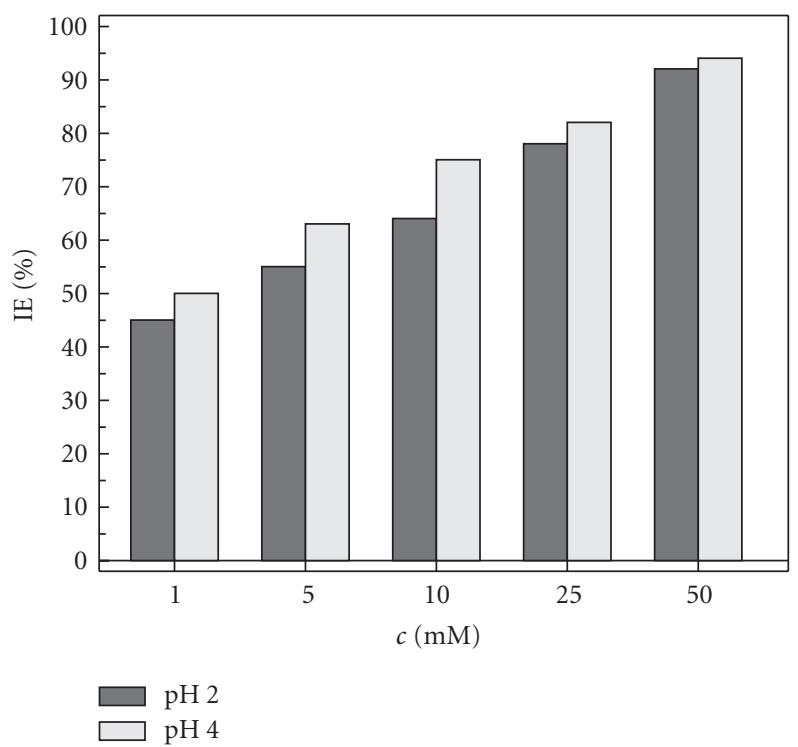

FIgURE 4: Inhibition efficiency of corrosion of copper in $0.5 \mathrm{M} \mathrm{PO}_{4}^{3-}$ solution with different concentrations of 1-Butyl-4methylpyridinium tetrafluoroborate of $\mathrm{pH} 2$ and 4.

The values of the copper corrosion rate in the absence and the presence of inhibitor for solution of both $\mathrm{pH}$ Values are presented in Table 2. The corrosion rate of copper is significantly reduced as a result of the reduction in the corrosion current densities. The protective layer on surface of metal causes that the corrosion rate to be more diminishes in case of less acid solution of phosphates.

3.2. Scanning Electron Microscopy Studies. The surface morphology of copper samples immersed in $0.5 \mathrm{M} \mathrm{PO}_{4}^{3-}$ ( $\mathrm{pH} 2$ and 4) for 24 hours in the absence and in the presence of $50.0 \mathrm{mM}$ of 1-Butyl-4-methylpyridinium tetrafluoroborate 
TABle 2: Corrosion rate of copper in $0.5 \mathrm{M} \mathrm{PO}_{4}^{3-}$ solutions in the absence or presence of different concentrations of 1-Butyl-4methylpyridinium tetrafluoroborate $\left(4 \mathrm{MBPBF}_{4}\right)$ of $\mathrm{pH} 2$ and 4 .

\begin{tabular}{lcc}
$\begin{array}{l}\text { Concentration of 1-Butyl- } \\
\text { 4-methylpyridinium } \\
\text { tetrafluoroborate } \\
(\mathrm{mM})\end{array}$ & \multicolumn{2}{c}{$k_{r}$ (mm/year) } \\
\hline 0 & $\mathrm{pH} \mathrm{2}$ & $\mathrm{pH} 4$ \\
\hline .0 & 0.67 & 0.46 \\
5.0 & 0.37 & 0.23 \\
10.0 & 0.31 & 0.18 \\
25.0 & 0.24 & 0.12 \\
50.0 & 0.15 & 0.08 \\
\hline
\end{tabular}

was studied by scanning electron microscopy (SEM). The solutions were not degassed.

Figure 5 show the surface morphology of copper specimens (a) before and (b) after being immersed in corrosive solution ( $\mathrm{pH}$ 2). The photograph (b) revels that the surface was strongly damaged in absence of the inhibitor. Figures 5(c) and 5(d) show SEM images of the surface copper specimens after immersion (for the same time interval) in corrosive solution containing additionally $50.0 \mathrm{mM}$ of 1Butyl-4-methylpyridinium tetrafluoroborate of $\mathrm{pH} 2$ and 4 , respectively. In the presence of the inhibitor the film precipitates on the surface of copper. The SEM photographs show that protective layer does not cover tightly the surface, and, hence does not protect the $\mathrm{Cu}$ surface to an adequate degree especially in case of solution of $\mathrm{pH}$ 2. Phosphate ions, oxygen and water penetrate the protective film through pores, flaws or other weak spots what results in the further corrosion of copper. In order to check the results of action by aggressive solution, the protective layer was removed from surface of copper. The layer was well adhered to the surface of the metal, and the removal of it was really difficult. Therefore ultrasonic water bath was used. The sample was shaken in diluted acetic acid and rinsed in propanol. Figure 5 presents samples after the removal of the inhibiting film for pH 4 (Figure 5(e)) and 2 (Figure 5(f)). However. However, received results indicated that more tight protective layer was forming in solution of $\mathrm{pH} 4$ (Figure 5(e)). Moreover, in phosphate solution the $4 \mathrm{MBPBF}_{4}$ acts better as the inhibitor in less acidic environment.

3.3. Mechanism of Corrosion Inhibition. Regarding the mechanism the oxygen reduction reaction on copper in acidic solutions a lot of work has been carried out [61-67]. The cathodic global reaction in an aerated aqueous phosphate solution could be described as follows:

$$
\mathrm{O}_{2}+4 \mathrm{H}^{+}+4 \mathrm{e}^{-} \longleftrightarrow 2 \mathrm{H}_{2} \mathrm{O}
$$

However, the first cathodic wave is attributed to reaction:

$$
\mathrm{O}_{2}+2 \mathrm{H}^{+}+2 \mathrm{e}^{-} \longleftrightarrow \mathrm{H}_{2} \mathrm{O}_{2} \text {. }
$$

In the more negative potential at the electrode, surface occurs the next reaction:

$$
\mathrm{H}_{2} \mathrm{O}_{2}+2 \mathrm{H}^{+}+2 \mathrm{e}^{-} \longleftrightarrow 2 \mathrm{H}_{2} \mathrm{O} \text {. }
$$

Furthermore, reaction (4a) is strongly influenced by potential [66].

The dissolution process of copper (anodic corrosion reaction) at low overpotentials runs according to the following steps [68-70]:

$$
\begin{gathered}
\mathrm{Cu}-\mathrm{e}^{-} \longleftrightarrow \mathrm{Cu}_{\mathrm{ads}}^{+}, \\
\mathrm{Cu}_{\mathrm{ads}}^{+}-\mathrm{e}^{-} \longleftrightarrow \mathrm{Cu}^{2+},
\end{gathered}
$$

where the $\mathrm{Cu}_{\mathrm{ads}}^{+}$is an adsorbed monovalent species of copper at the electrode surface.

The inhibition effect of 1-Butyl-4-methylpyridinium tetrafluoroborate on the copper surface could be explained as follows

The inhibitor of $4 \mathrm{MBPBF}_{4}$ can be protonated in acidic solutions:

$$
4 \mathrm{MBPBF}_{4}+\mathrm{H}^{+} \longleftrightarrow\left[4 \mathrm{MBPBHF}_{4}\right]^{+}
$$

Then the inhibitor molecules adsorb through electrostatic interactions between the negatively charged copper surface and positively charged $\left[4 \mathrm{MBPBHF}_{4}\right]^{+}$. However, the electrode carried the negative charge, therefore $\left[4 \mathrm{MBPBHF}_{4}\right]^{+}$ ions should be first adsorbed directly on copper to probably form a protective layer at active sites:

$$
\mathrm{Cu}+[4 \mathrm{MBPBHF} 4]^{+} \longleftrightarrow\left[\mathrm{Cu}-4 \mathrm{MBPBF}_{4}\right]_{\mathrm{ads}}+\mathrm{H}^{+},
$$

and blocks the further oxidation reaction of $\mathrm{Cu}_{\mathrm{ads}}^{+}$to $\mathrm{Cu}^{2+}$ (reaction (5b)). Moreover, the inhibitor molecules lead to the blocking of the transfer of oxygen from the bulk solution to the copper/solution interface that is going to reduce the cathodic reaction of oxygen (reaction (4a)). This indicates that the presence in phosphate solution of $4 \mathrm{MBPBF}_{4}$ affects both the cathodic and anodic reactions, therefore the, compound acts as a mixed-type inhibitor. The proposed mechanism of corrosion inhibition of copper by $4 \mathrm{MBPBF}_{4}$ in phosphate solutions (reactions (4a)-(5a)) requires the confirmation through making additional research.

However, exhausting information regarding mechanism of corrosion inhibition can be obtained on the basis of thermodynamic measurements.

3.4. Effect of Temperature. The effect of temperature on the corrosion of copper in $0.5 \mathrm{MPO}_{4}^{3-}$ solution in the absence and presence of $10.0 \mathrm{mM}$ of 1-Butyl-4-methylpyridinium tetrafluoroborate of $\mathrm{pH} 2$ and 4 at temperature ranging from 303 to $343 \mathrm{~K}$ was investigated by potentiodynamic polarization measurements. The corrosion parameters and the inhibition efficiency are presented in Table 3. The corrosion potential and cathodic and anodic Tafel slope change similarly in case of low temperature of solutions (Table 1). Therefore, the growth of temperature of solutions does not influence the change of inhibition mechanism. Worth 


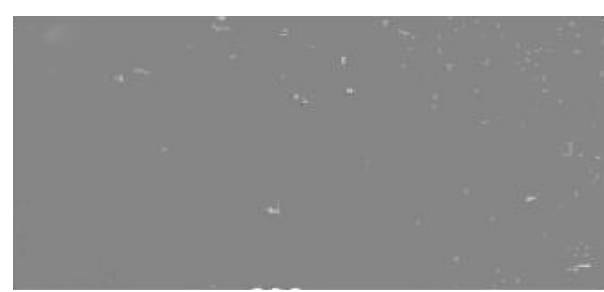

(a)

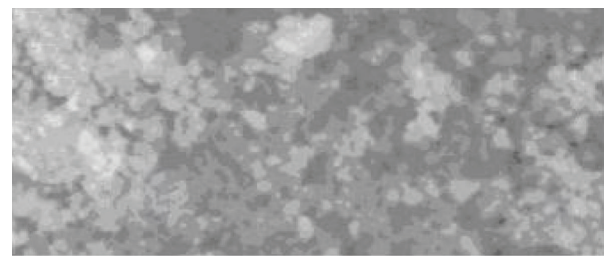

(c)

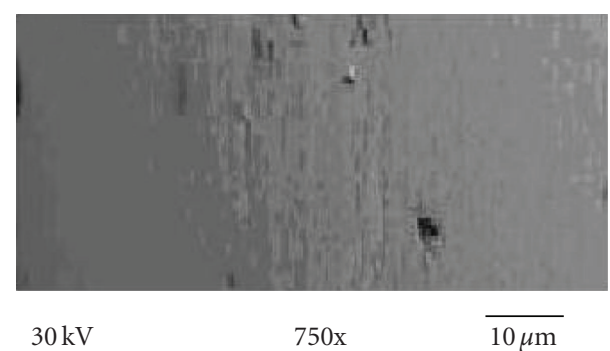

(e)

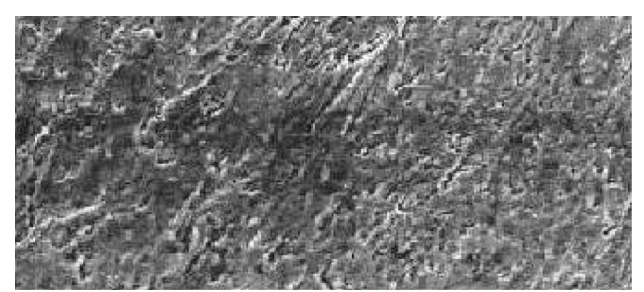

(b)

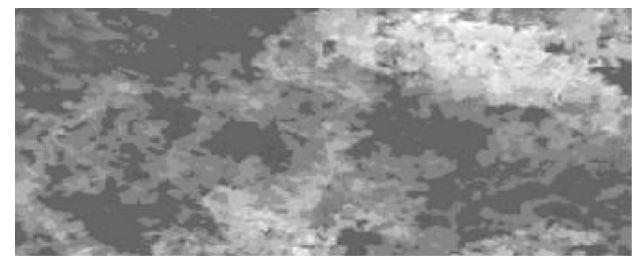

(d)

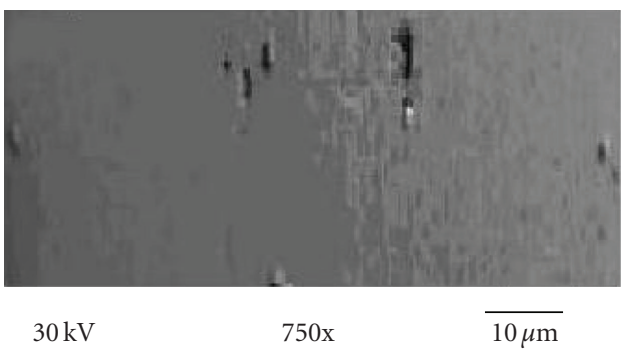

(f)

FIGURE 5: SEM micrographs of the surface of copper: (a) before, (b) after being immersed in $0.5 \mathrm{M} \mathrm{PO}_{4}^{3-}$ (pH 2) for 24 hours, (c), (d) corrosive solution contained additionally $50.0 \mathrm{mM}$ of 1-Butyl-4-methylpyridinium tetrafluoroborate of $\mathrm{pH} 4$ and 2 , respectively, after removal of the inhibiting film for $\mathrm{pH}$ : (e) 4 and (f) 2 (magnification $750 \mathrm{x}$ ).

noticing is that the corrosion current density increases and inhibition efficiency decreases with increasing temperature, which indicates desorption of the inhibitor molecules from the surface of copper with rising temperature of solutions.

3.4.1. Thermodynamic Activation Parameters. Thermodynamic activation parameters are important to study the inhibitive mechanism. The mechanism of the inhibitor action can be deduced by comparing the apparent activation energies, $E_{a}$, in the presence and absence of the corrosion inhibitor. Activation parameters such as $E_{a}$, the enthalpy of activation, $\Delta H_{a}$, and the entropy of activation, $\Delta S_{a}$, were calculated from an Arrhenius-type plot [71, 72]:

$$
j_{\text {corr }}=A \exp \left(\frac{-E_{a}}{R T}\right),
$$

where $A$ is the Arrhenius constant, $E_{a}$ is the apparent activation energy, $R$ is the universal gas constant, and $T$ is the absolute temperature. An alternative formula of the Arrhenius equation is the transition state equation [73]:

$$
j_{\text {corr }}=\left(\frac{R T}{N h}\right) \exp \left(\frac{\Delta S_{a}}{R}\right) \exp \left(\frac{-\Delta H_{a}}{R T}\right),
$$

where $N$ is the Avogadro's constant, $h$ is the Planck's constant, $\Delta S_{a}$ is the change of entropy for activation, and
$\Delta H_{a}$ is the change of enthalpy for activation. Plots of $\ln \left(j_{\text {corr }}\right)$ versuss $1 / T$, and $\ln \left(j_{\text {corr }} / T\right)$ versus $1 / T$ give straight lines with slopes of $-E_{a} / R$ and $1 / \mathrm{T} \Delta H_{a} / R$, respectively. The intercepts, which can then be calculated, will be $[\ln (R / N h)+$ $\left.\left(\Delta S_{a} / R\right)\right]$ for the Arrhenius and transition-state equations, respectively. Figures 6 and 7 represent the data plots in the absence and presence of $4 \mathrm{MBPBF}_{4}$ of $\mathrm{pH} 2$ and 4 . The calculated thermodynamic activation parameters are listed in Table 4. The values of $E_{a}$ and $\Delta H_{a}$ in the presence of $10.0 \mathrm{mM} 4 \mathrm{MBPBF}_{4}$ are higher than those in black solutions, indicating that more energy barrier for the reaction in the presence of $4 \mathrm{MBPBF}_{4}$ is attained, especially in case of $\mathrm{pH} 4$. This shows that the energy barrier of the corrosion reaction increased in the presence of the inhibitor without changing the mechanism of dissolution of copper [74]. The entropy of activation, $\Delta S_{a}$, in the absence and presence of $4 \mathrm{MBPBF}_{4}$ is large and negative (especially with $\mathrm{pH} 4$ ), implying that the rate-determining step for the activated complex is the association rather than the dissociation step, which means that a decrease in disordering takes place by going from reactants to the activated complex [75].

3.5. Adsorption Isotherm. It has been assumed that inhibitor molecules establish their inhibition action via the adsorption of the inhibitor onto the metal surface. The adsorption processes of inhibitors are influenced by the chemical 
TABLE 3: Corrosion parameters and inhibition efficiency of copper electrode in $0.5 \mathrm{M} \mathrm{PO}_{4}^{3-}$ solutions in the absence or presence of $10.0 \mathrm{mM}$ of 1-Butyl-4-methylpyridinium tetrafluoroborate $\left(4 \mathrm{MBPBF}_{4}\right)$ of $\mathrm{pH} 2$ and 4 at different temperatures.

\begin{tabular}{|c|c|c|c|c|c|c|c|}
\hline Inhibitor & $\mathrm{pH}$ & Temperature $(\mathrm{K})$ & $-E_{\text {corr }}(\mathrm{mV})$ & $j_{\text {corr }}\left(\mu \mathrm{A} \mathrm{cm}^{-2}\right)$ & $-b_{c}\left(\mathrm{mV} \mathrm{dec}{ }^{-1}\right)$ & $b_{a}\left(\mathrm{mV} \mathrm{\operatorname {dec } ^ { - 1 } )}\right.$ & IE $(\%)$ \\
\hline \multirow{6}{*}{ Blank } & \multirow{10}{*}{2} & 303 & 66 & 41.0 & 297 & 76 & - \\
\hline & & 313 & 79 & 53.5 & 299 & 76 & - \\
\hline & & 323 & 85 & 65.0 & 301 & 79 & - \\
\hline & & 333 & 94 & 77.3 & 306 & 82 & - \\
\hline & & 343 & 104 & 89.1 & 304 & 83 & - \\
\hline & & 303 & 101 & 15.1 & 276 & 66 & 63.1 \\
\hline \multirow{4}{*}{$4 \mathrm{MBPBF}_{4}$} & & 313 & 109 & 22.4 & 279 & 69 & 58.1 \\
\hline & & 323 & 117 & 30.6 & 270 & 72 & 52.9 \\
\hline & & 333 & 124 & 39.9 & 279 & 74 & 48.4 \\
\hline & & 343 & 132 & 49.7 & 282 & 74 & 44.2 \\
\hline \multirow{6}{*}{ Blank } & \multirow{10}{*}{4} & 303 & 69 & 29.0 & 241 & 163 & - \\
\hline & & 313 & 78 & 36.3 & 240 & 163 & - \\
\hline & & 323 & 87 & 47.2 & 243 & 166 & - \\
\hline & & 333 & 97 & 57.5 & 246 & 169 & - \\
\hline & & 343 & 115 & 67.0 & 248 & 170 & - \\
\hline & & 303 & 286 & 7.5 & 121 & 392 & 74.1 \\
\hline \multirow{4}{*}{$4 \mathrm{MBPBF}_{4}$} & & 313 & 295 & 11.0 & 123 & 401 & 69.6 \\
\hline & & 323 & 302 & 16.9 & 126 & 406 & 64.1 \\
\hline & & 333 & 311 & 23.6 & 128 & 408 & 59.0 \\
\hline & & 343 & 319 & 30.7 & 130 & 411 & 54.2 \\
\hline
\end{tabular}

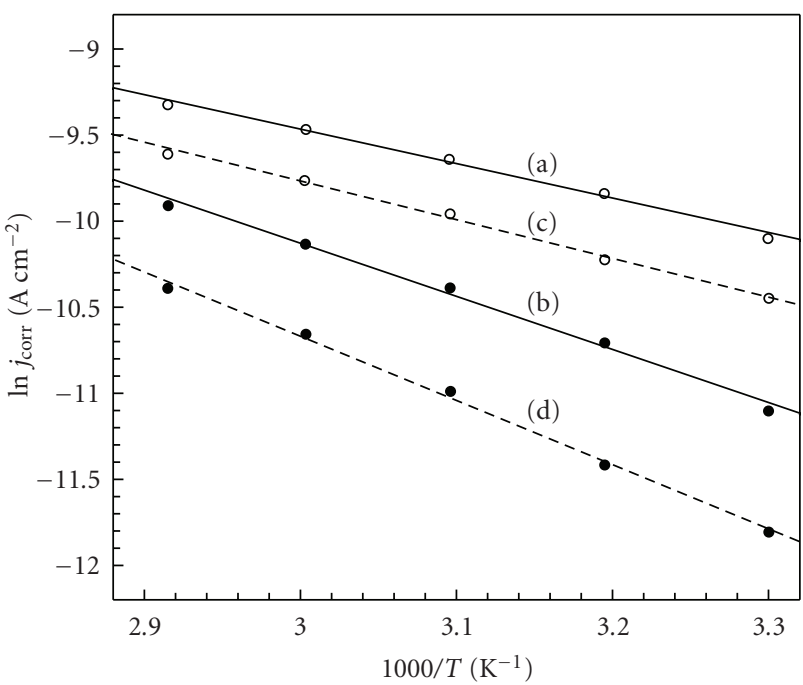

FIGURE 6: Arrhenius plots for copper in $0.5 \mathrm{M} \mathrm{PO}_{4}^{3-}$ solutions containing: (a), (c) 0 and (b), (d) $10.0 \mathrm{mM}$ of 1-Butyl-4methylpyridinium tetrafluoroborate. The $\mathrm{pH}$ of solutions was the following: (a), (b) 2 and (c), (d) 4 .

structure of organic compounds, the nature and surface change of metal, the distribution of charge in molecule and the type of aggressive media [76]. The adsorption isotherm can provide the basic information on the interaction between the inhibitor and the metal surface, which depends on the degree of surface coverage, $\Theta$ [77]. The values of

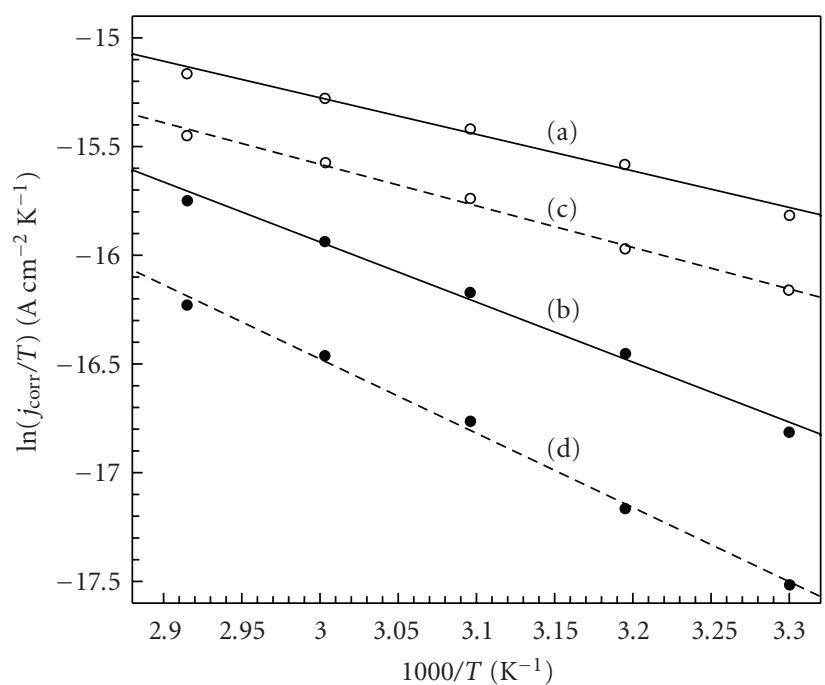

FIgure 7: Transition state plots for copper in $0.5 \mathrm{M} \mathrm{PO}_{4}^{3-}$ solutions containing: (a), (c) 0 and (b), (d) $10.0 \mathrm{mM}$ of 1-Butyl-4methylpyridinium tetrafluoroborate. The $\mathrm{pH}$ of solutions was the following: (a), (b) 2 and (c), (d) 4 .

surface coverage for different concentrations of inhibitor in $0.5 \mathrm{M} \mathrm{PO}_{4}^{3-}$ solutions of $\mathrm{pH} 2$ and 4 were evaluated from polarization curves according equation

$$
\Theta=1-\frac{j_{\text {corr }}}{j_{o}} .
$$


TABLE 4: Thermodynamic activation parameters for copper in $0.5 \mathrm{M} \mathrm{PO}_{4}^{3-}$ solutions in the absence or presence of $10.0 \mathrm{mM}$ of 1Butyl-4-methylpyridinium tetrafluoroborate $\left(4 \mathrm{MBPBF}_{4}\right)$ for $\mathrm{pH} 2$ and 4.

\begin{tabular}{lcccc}
\hline Inhibitor & $\mathrm{pH}$ & $E_{a}\left(\mathrm{~kJ} \mathrm{~mol}^{-1}\right)$ & $\Delta H_{a}\left(\mathrm{~kJ} \mathrm{~mol}^{-1}\right)$ & $\begin{array}{c}\Delta S_{a} \\
\left(\mathrm{~J} \mathrm{~mol}^{-1} \mathrm{~K}^{-1}\right)\end{array}$ \\
\hline Blank & 2 & 16.64 & 13.98 & -282.65 \\
$4 \mathrm{MBPBF}_{4}$ & & 25.66 & 22.98 & -261.19 \\
Blank & 4 & 18.47 & 15.81 & -297.69 \\
$4 \mathrm{MBPBF}_{4}$ & & 31.02 & 28.33 & -249.59 \\
\hline
\end{tabular}

TABLE 5: Surface coverage of copper electrode in $0.5 \mathrm{M} \mathrm{PO}_{4}^{3-}$ solutions for different concentrations of 1-Butyl-4-methylpyridinium tetrafluoroborate $\left(4 \mathrm{MBPBF}_{4}\right)$ for $\mathrm{pH} 2$ and 4.

\begin{tabular}{llcccc}
\hline \multicolumn{5}{c}{ Concentration } \\
$\mathrm{pH}$ & 1.0 & 5.0 & 10.0 & 25.0 & 50.0 \\
& $(\mathrm{mM})$, & 1-Butyl-4-methylpyridinium & tetrafluoroborate \\
\hline 2 & 0.45 & 0.55 & 0.64 & 0.78 & 0.92 \\
4 & 0.50 & 0.63 & 0.75 & 0.82 & 0.94 \\
\hline
\end{tabular}

TABLE 6: Slope $(b)$, linear correlation coefficient $\left(R^{2}\right)$, equilibrium constant $(K)$, and standard free energy of adsorption $\left(\Delta G_{\text {ads }}^{0}\right)$ in $0.5 \mathrm{M} \mathrm{PO}_{4}^{3-}$ of 1-Butyl-4-methylpyridinium tetrafluoroborate $\left(4 \mathrm{MBPBF}_{4}\right)$ solutions of $\mathrm{pH} 2$ and 4.

\begin{tabular}{lcccc}
\hline $\mathrm{pH}$ & $b$ & $R^{2}$ & $K\left(\mathrm{M}^{-1}\right)$ & $\begin{array}{c}\Delta G_{\mathrm{ads}}^{0} \\
\left(\mathrm{~kJ} \mathrm{~mol}^{-1}\right)\end{array}$ \\
\hline 2 & 1.00 & 0.9998 & $2.2 \times 10^{2}$ & -23.3 \\
4 & 1.01 & 0.9998 & $3.8 \times 10^{2}$ & -24.7 \\
\hline
\end{tabular}

The values of the degree of surface coverage are listed in Table 5. It can be seen that the values of $\Theta$ increased with an increase in the concentration of $4 \mathrm{MBPBF}_{4}$. It is also worth to notice that the degree of surface coverage is higher in case of solutions of $\mathrm{pH} 4$ (Table 5). Using these values of $\Theta$, different adsorption isotherms can be used to deal with the experimental data. The Langmuir adsorption isotherm $[78,79]$ was applied to investigate the adsorption of $4 \mathrm{MBPBF}_{4}$ on copper surface given by the following equation:

$$
\frac{c}{\Theta}=\frac{1}{K}+c
$$

where $K$ is the adsorption equilibrium constant and $c$ is the concentration of inhibitor.

Figure 8 represents the adsorption plots of 1-Butyl-4methylpyridinium tetrafluoroborate on copper. It should be explained that other adsorption ishotherms (Frumkin and Temkin) were checked. The linear correlation coefficient was used to choose the isotherm that best fits the experimental data. It should be noted that the data fits the straight line with a slope nearly equal unity with linear correlation coefficient higher than 0.999 (Table 6) indicating that these inhibitors adsorb according to the Langmuir adsorption isotherm.

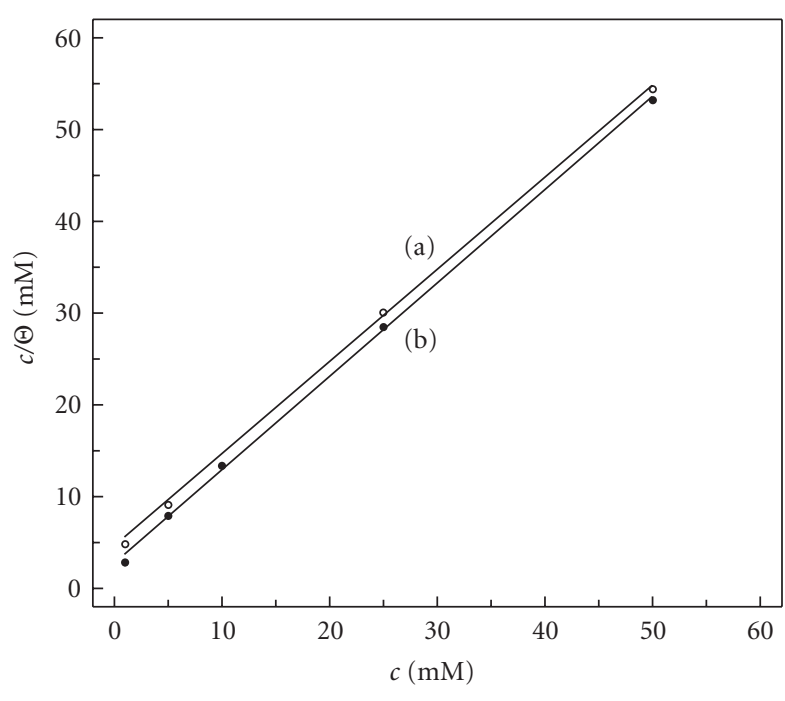

FIGURE 8: Adsorption isotherm of 1-Butyl-4-methylpyridinium tetrafluoroborate on the copper surface in $0.5 \mathrm{M} \mathrm{PO}_{4}^{3-}$ solutions of pH: (a) 2 and (b) 4 .

The nature of corrosion inhibition has been deduced in terms of the adsorption characteristics of the inhibitor. The metal surface in aqueous solution is always covered with adsorbed water dipoles. The adsorption of inhibitor molecules from aqueous solution is a quasi-substitution process between the organic compounds in the aqueous phase and water molecules at the electrode surface [80]. The Langmuir isotherm is based on the assumption that each site of metal surface holds one adsorbed species:

$$
4 \mathrm{MBPBF}_{4(\text { sol })}+\mathrm{H}_{2} \mathrm{O}_{(\mathrm{ads})} \longleftrightarrow 4 \mathrm{MBPBF}_{4(\mathrm{ads})}+\mathrm{H}_{2} \mathrm{O}_{(\mathrm{sol})} .
$$

In this situation, the adsorption of of one molecule of $4 \mathrm{MBPBF}_{4}$ is accompanied by desorption one molecule of $\mathrm{H}_{2} \mathrm{O}$ from the surface of copper. This kind of isotherm involves the assumption of no interaction between the adsorbed species on the metal surface.

A graph $c / \Theta$ against $c$ leads to values of $K$, as the equilibrium constant of the adsorption process (Figure 8). The free energies of adsorption, $\Delta G_{\text {ads }}^{0}$ were calculated from the adsorption equilibrium constant using the equation [81]:

$$
\Delta G_{\mathrm{ads}}^{0}=-R T \ln (55.5 \times K),
$$

where value 55.5 is the molar concentration of water in the solution.

The adsorption equilibrium constant and the standard free energy of adsorption of $4 \mathrm{BMPBF}_{4}$ for solutions of $\mathrm{pH} 2$ and 4 on copper are presented in Table 6 . The values of $K$ are relatively low, meaning that interactions between 1-Butyl-4methylpyridinium tetrafluoroborate and the metal surface are weaker. The negative values of $\Delta G_{\mathrm{ads}}^{0}$ mean that the adsorption of $4 \mathrm{MBPBF}_{4}$ on copper surface is a spontaneous process, and indicates the strong interaction between the inhibitor molecules and the copper surface [82].

Generally, values of $\Delta G_{\text {ads }}^{0}$ around $-40 \mathrm{~kJ} \mathrm{~mol}^{-1}$ or lower are consistent with the electrostatic interaction between the 
TABLE 7: Thermodynamic adsorption parameters for copper in $0.5 \mathrm{M} \mathrm{PO}_{4}^{3-}$ solutions in the presence of $10.0 \mathrm{mM}$ of 1-Butyl-4methylpyridinium tetrafluoroborate $\left(4 \mathrm{MBPBF}_{4}\right)$ for $\mathrm{pH} 2$ and 4 at different temperatures.

\begin{tabular}{cccccc}
\hline $\mathrm{pH}$ & $\begin{array}{c}\text { Temperature } \\
(K)\end{array}$ & $\begin{array}{c}K \times 10^{-2} \\
\left(M^{-1}\right)\end{array}$ & $\begin{array}{c}\Delta G_{\mathrm{ads}}^{0} \\
\left(\mathrm{~kJ} \mathrm{~mol}^{-1}\right)\end{array}$ & $\begin{array}{c}\Delta H_{\mathrm{ads}}^{0} \\
\left(\mathrm{~kJ} \mathrm{~mol}^{-1}\right)\end{array}$ & $\begin{array}{c}\Delta S_{\mathrm{ads}}^{0} \\
\left(\mathrm{~J} \mathrm{~mol}^{-1} \mathrm{~K}^{-1}\right)\end{array}$ \\
\hline \multirow{4}{*}{2} & 303 & 1.71 & -22.69 & & 20.14 \\
& 313 & 1.39 & -22.17 & & 18.40 \\
& 323 & 1.12 & -21.65 & -16.69 & 16.65 \\
& 333 & 0.93 & -21.20 & & 15.15 \\
& 343 & 0.79 & -20.78 & & 13.74 \\
\hline \multirow{4}{*}{4} & 303 & 2.86 & -23.97 & & 15.76 \\
& 313 & 2.29 & -23.41 & & 13.91 \\
& 323 & 1.79 & -22.80 & -19.27 & 11.84 \\
& 333 & 1.44 & -22.26 & & 10.04 \\
& 343 & 1.18 & -21.78 & & 8.42 \\
\hline
\end{tabular}

charged molecules and the charged metal surface (physisorption) [83-85]. For investigated inhibitor the values of $\Delta G_{\text {ads }}^{0}$ equal -23.6 and $-24.7 \mathrm{~kJ} \mathrm{~mol}^{-1}$ for solutions of $\mathrm{pH} 2$ and 4 , respectively (Table 6). The results indicate the $4 \mathrm{MBPBF}_{4}$ to be physically adsorbed on the copper surface. The adsorption of the inhibitor at the metal surface is the first step in the action mechanism of inhibitors in aggressive acid media. The adsorption of 1-Butyl-4-methylpyridinium tetrafluoroborate on the copper surface makes a barrier for mass and charge transfers. This situation leads to the protection of the copper surface against the attack of aggressive solution.

3.6. Thermodynamic Adsorption Parameters. Thermodynamically, the free energy of adsorption, $\Delta G_{\text {ads }}^{0}$, is related to the standard enthalpy, $\Delta H_{\mathrm{ads}}^{0}$ and entropy, $\Delta S_{\mathrm{ads}}^{0}$ of the adsorption process as follows $[86,87]$ :

$$
\Delta G_{\mathrm{ads}}^{0}=\Delta H_{\mathrm{ads}}^{0}-T \Delta S_{\mathrm{ads}}^{0} .
$$

Moreover, the standard enthalpy of adsorption could be calculated according to the Van't Hoff equation

$$
\ln \mathrm{K}=-\frac{\Delta H_{\mathrm{ads}}^{0}}{R T}+\text { const. }
$$

The adsorption equilibrium constant is related to the degree of surface coverage by:

$$
K=\frac{\Theta}{c(1-\Theta)} .
$$

It should be noted that the $K$ decreases with increasing temperature, (Table 7). This confirms earlier made admission that the molecules of $4 \mathrm{MBPBF}_{4}$ are physically adsorbed on surface of copper. However, desorption process of inhibitor enhances with raising of the temperature of the solution. The free energies of adsorption of 1-Butyl-4-methylpyridinium tetrafluoroborate were calculated at different temperatures (11) and are given in Table 7. The values of $\Delta G_{\text {ads }}^{0}$ are around $-20 \mathrm{~kJ} \mathrm{~mol}^{-1}$ indicating that the adsorption mechanism

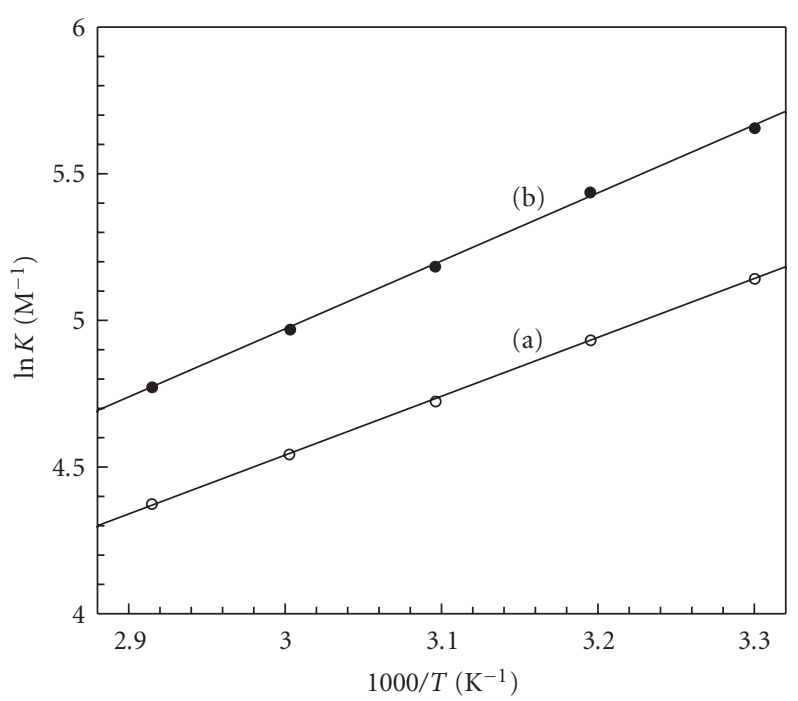

Figure 9: The Van't Hoff plots for the copper in $0.5 \mathrm{M} \mathrm{PO}_{4}^{3-}$ solutions containing $10.0 \mathrm{mM}$ of 1-Butyl-4-methylpyridinium tetrafluoroborate. The $\mathrm{pH}$ of solutions was as the following: (a) 2 and (b) 4 .

of $4 \mathrm{MBPBF}_{4}$ in $0.5 \mathrm{MPO}_{4}^{3-}$ solution of $\mathrm{pH} 2$ or 4 is physisorption at the studied temperatures.

A plot $\ln K$ versus 1000/ $T$ gives of straight lines, as shown in Figure 9. The slope of the straight line is $-\Delta H_{\mathrm{ads}}^{0} / R$. The values of the standard enthalpy are given also in Table 7 . The $\Delta H_{\mathrm{ads}}^{0}$ values are negative, for that reason adsorption of 1-Butyl-4-methylpyridinium tetrafluoroborate molecules onto the $\mathrm{Cu}$ surface is an exothermic process. Moreover, the values of $\Delta H_{\text {ads }}^{0}$ are less than $-40 \mathrm{~kJ} \mathrm{~mol}^{-1}$ [88], therefore, once again implying that in investigated solutions, physical adsorption is taking place.

The standard entropy of inhibitor adsorption, $\Delta S_{\text {ads }}^{0}$ can be calculated from (12). The values of $\Delta S_{\text {ads }}^{0}$, are recorded in Table 7 . The positive values of $\Delta S_{\mathrm{ads}}^{0}$ mean that the increase in disordering takes place by going from reactants to the $\mathrm{Cu} /$ solution interface, which is the driving force for the adsorption of 1-Butyl-4-methylpyridinium tetrafluoroborate onto the copper surface [89].

\section{Conclusion}

The following results can be drawn from this study.

(1) The investigated 1-Butyl-4-methylpyridinium tetrafluoroborate $\left(4 \mathrm{MBPBF}_{4}\right)$ exhibits inhibiting properties for the corrosion of copper in $0.5 \mathrm{M} \mathrm{PO}_{4}^{3-}$ solutions of $\mathrm{pH} 2$ and 4.

(2) The inhibition efficiency (IE(\%)) increased with the increase in inhibitor concentration but decreases with increasing temperature. IE at all concentrations of $4 \mathrm{MBPBF}_{4}$ followed the order of $\mathrm{pH}: 4>2$.

(3) The of 1-Butyl-4-methylpyridinium tetrafluoroborate acts as a mixed-type inhibitor, independently from $\mathrm{pH}$ solutions. 
(4) The corrosion inhibition action of 1-Butyl-4methylpyridinium tetrafluoroborate is mainly due to adsorption of $4 \mathrm{MBPBF}_{4}$ on the surface of copper.

(5) The adsorption of the investigated compound obeys the Langmuir adsorption isotherm.

(6) The thermodynamic functions of corrosion indicate that of 1-Butyl-4-methylpyridinium tetrafluoroborate adsorbs on the copper surface by a physisorption-based mechanism involving a spontaneous and exothermic process.

\section{Acknowledgment}

The authors would like to thank Professor M. Hepel from the Department of Chemistry SUNY at Potsdam, USA for the helpful discussions and a critical reading of the paper.

\section{References}

[1] G. Trabanelli, "Inhibitors. An old remedy for a new challenge," Corrosion, vol. 47, no. 6, pp. 410-419, 1991.

[2] A. Jardy, A. Legal Lasalle-Molin, M. Keddam, and H. Takenouti, "Copper dissolution in acidic sulphate media studied by QCM and rrde under ac signal," Electrochimica Acta, vol. 37, no. 12, pp. 2195-2201, 1992.

[3] G. Banerjee and S. N. Malhotra, "Contribution to adsorption of aromatic amines on mild steel surface from $\mathrm{HCl}$ solutions by impedance, UV, and Raman spectroscopy," Corrosion, vol. 48, no. 1, pp. 10-15, 1992.

[4] S. T. Arab and E. A. Noor, "Inhibition of acid corrosion of steel by some S-alkylisothiouronium iodides," Corrosion, vol. 49, no. 2, pp. 122-129, 1993.

[5] D. D. N. Singh and A. K. Dey, "Synergistic effects of inorganic and organic cations on inhibitive performance of propargyl alcohol on steel dissolution in boiling hydrochloric acid solution," Corrosion, vol. 49, no. 7, pp. 594-600, 1993.

[6] S. Martinez, "Inhibitory mechanism of mimosa tannin using molecular modeling and substitutional adsorption isotherms," Materials Chemistry and Physics, vol. 77, no. 1, pp. 97-102, 2003.

[7] M. Özcan, I. Dehri, and M. Erbil, "Organic sulphurcontaining compounds as corrosion inhibitors for mild steel in acidic media: correlation between inhibition efficiency and chemical structure," Applied Surface Science, vol. 236, no. 1, pp. 155-164, 2004.

[8] H. Ashassi-Sorkhabi, B. Shaabani, and D. Seifzadeh, "Effect of some pyrimidinic Shciff bases on the corrosion of mild steel in hydrochloric acid solution," Electrochimica Acta, vol. 50, no. 16-17, pp. 3446-3452, 2005.

[9] J. Cruz, T. Pandiyan, and E. García-Ochoa, "A new inhibitor for mild carbon steel: electrochemical and DFT studies," Journal of Electroanalytical Chemistry, vol. 583, no. 1, pp. 816, 2005.

[10] L. Larabi, O. Benali, S. M. Mekelleche, and Y. Harek, "2Mercapto-1-methylimidazole as corrosion inhibitor for copper in hydrochloric acid," Applied Surface Science, vol. 253, no. 3, pp. 1371-1378, 2006.
[11] J. Cruz, R. Martínez, J. Genesca, and E. García-Ochoa, "Experimental and theoretical study of 1-(2-ethylamino)-2methylimidazoline as an inhibitor of carbon steel corrosion in acid media," Journal of Electroanalytical Chemistry, vol. 566, no. 1, pp. 111-121, 2004.

[12] A. M. S. Abdennabi, A. I. Abdulhadi, S. T. Abu-Orabi, and H. Saricimen, "The inhibition action of 1(benzyl)1-H-4,5dibenzoyl-1,2,3-triazole on mild steel in hydrochloric acid media," Corrosion Science, vol. 38, no. 10, pp. 1791-1800, 1996.

[13] F. Bentiss, M. Traisnel, L. Gengembre, and M. Lagrenée, "New triazole derivative as inhibitor of the acid corrosion of mild steel: electrochemical studies, weight loss determination, SEM and XPS," Applied Surface Science, vol. 152, no. 3, pp. 237-249, 1999.

[14] L. Wang, "Inhibition of mild steel corrosion in phosphoric acid solution by triazole derivatives," Corrosion Science, vol. 48, no. 3, pp. 608-616, 2006.

[15] S. Kertit and B. Hammouti, "Corrosion inhibition of iron in $1 \mathrm{M} \mathrm{HCl}$ by 1-phenyl-5-mercapto-1,2,3,4-tetrazole," Applied Surface Science, vol. 93, no. 1, pp. 59-66, 1996.

[16] R. M. Hudson, T. J. Butler, and C. J. Warning, "The effect of pyrrole-halide mixtures in inhibiting the dissolution of low-carbon steel in sulphuric acid," Corrosion Science, vol. 17, no. 7, pp. 571-581, 1977.

[17] M. A. Veloz and I. G. Martínez, "Effect of some pyridine derivatives on the corrosion behavior of carbon steel in an environment like NAGE TM0177," Corrosion, vol. 62, no. 4, pp. 283-292, 2006.

[18] A. Ouchrif, M. Zegmout, B. Hammouti, S. El-Kadiri, and A. Ramdani, "1,3-Bis(3-hyroxymethyl-5-methyl-1-pyrazole) propane as corrosion inhibitor for steel in $0.5 \mathrm{M} \mathrm{H}_{2} \mathrm{SO}_{4}$ solution," Applied Surface Science, vol. 252, no. 2, pp. 339-344, 2005.

[19] A. Chetouani, B. Hammouti, T. Benhadda, and M. Daoudi, "Inhibitive action of bipyrazolic type organic compounds towards corrosion of pure iron in acidic media," Applied Surface Science, vol. 249, no. 1-4, pp. 375-385, 2005.

[20] S. A. Abd El-Maksoud, "The influence of some Arylazobenzoyl acetonitrile derivatives on the behaviour of carbon steel in acidic media," Applied Surface Science, vol. 206, no. 1-4, pp. 129-136, 2003.

[21] A. Chetouani, A. Aouniti, B. Hammouti, N. Benchat, T. Benhadda, and S. Kertit, "Corrosion inhibitors for iron in hydrochloride acid solution by newly synthesised pyridazine derivatives," Corrosion Science, vol. 45, no. 8, pp. 1675-1684, 2003.

[22] M. Ohsawa and W. Suëtaka, "Spectro-electrochemical studies of the corrosion inhibition of copper by mercaptobenzothiazole," Corrosion Science, vol. 19, no. 7, pp. 709-722, 1979.

[23] G. W. Walter, "A review of impedance plot methods used for corrosion performance analysis of painted metals," Corrosion Science, vol. 26, no. 9, pp. 681-703, 1986.

[24] B. Trachli, M. Keddam, H. Takenouti, and A. Srhiri, "Protective effect of electropolymerized 3-amino 1,2,4-triazole towards corrosion of copper in $0.5 \mathrm{M} \mathrm{NaCl}$," Corrosion Science, vol. 44, no. 5, pp. 997-1008, 2002.

[25] M. Hepel and M. Scendo, "Growth kinetics of multi-layer CuEtX films on copper piezoelectrodes," in Thin Films: Preparation, Characterization, Applications, M. P. Soriaga, J. Stickney, L. A. Bottomley, and Y.-G. Kim, Eds., Kluwer Academic/Plenum Publishers, New York, NY, USA, 2001.

[26] M. Hepel and M. Scendo, "Kinetics of CuEtX film formation on copper piezoelectrodes," Journal of Electroanalytical Chemistry, vol. 538-539, pp. 121-132, 2002. 
[27] M. Scendo, "Potassium ethyl xanthate as corrosion inhibitor for copper in acidic chloride solutions," Corrosion Science, vol. 47, no. 7, pp. 1738-1749, 2005.

[28] M. Scendo, "Corrosion inhibition of copper by potassium ethyl xanthate in acidic chloride solutions," Corrosion Science, vol. 47, no. 11, pp. 2778-2791, 2005.

[29] M. Scendo, D. Poddebniak, and J. Malyszko, "Indole and 5chloroindole as inhibitors of anodic dissolution and cathodic deposition of copper in acidic chloride solutions," Journal of Applied Electrochemistry, vol. 33, no. 3-4, pp. 287-293, 2003.

[30] A. A. Aksüt and S. Bilgiç, "The effect of amino acids on the corrosion of nickel in $\mathrm{H}_{2} \mathrm{SO}_{4}$," Corrosion Science, vol. 33, no. 3, pp. 379-387, 1992.

[31] H. Baba and T. Kodama, "Corrosion inhibition and characteristics of the triazinedithiol surface film on copper under potentiostatic anodization," Corrosion Science, vol. 41, no. 10 , pp. 1987-2000, 1999.

[32] G. Moretti and F. Guidi, "Tryptophan as copper corrosion inhibitor in $0.5 \mathrm{M}$ aerated sulfuric acid," Corrosion Science, vol. 44, no. 9, pp. 1995-2011, 2002.

[33] J. B. Matos, L. P. Pereira, S. M. L. Agostinho, O. E. Barcia, G. G. O. Cordeiro, and E. D'Elia, "Effect of cysteine on the anodic dissolution of copper in sulfuric acid medium," Journal of Electroanalytical Chemistry, vol. 570, no. 1, pp. 91-94, 2004.

[34] M. Scendo, "The effect of purine on the corrosion of copper in chloride solutions," Corrosion Science, vol. 49, no. 2, pp. 373-390, 2007.

[35] M. Scendo, "The influence of adenine on corrosion of copper in chloride solutions," Corrosion Science, vol. 50, no. 7, pp. 2070-2077, 2008.

[36] M. Scendo, "Inhibitive action of the purine and adenine for copper corrosion in sulphate solutions," Corrosion Science, vol. 49, no. 7, pp. 2985-3000, 2007.

[37] M. Scendo, "Inhibition of copper corrosion in sodium nitrate solutions with nontoxic inhibitors," Corrosion Science, vol. 50, no. 6, pp. 1584-1592, 2008.

[38] S. Muralidharan and S. Venkatakrishna Iyer, "The influence of $\mathrm{N}$-heterocyclics on corrosion inhibition and hydrogen permeation through mild steel in acidic solutions," Anti-Corrosion Methods and Materials, vol. 44, no. 2, pp. 100-106, 1997.

[39] R. Gašparac, C. R. Martin, and E. Stupnišek-Lisac, "In situ studies of imidazole and its derivatives as copper corrosion inhibitors I. Activation energies and thermodynamics of adsorption," Journal of the Electrochemical Society, vol. 147, no. 2, pp. 548-551, 2000.

[40] D. Q. Zhang, L. X. Gao, and G. D. Zhou, "Inhibition of copper corrosion in aerated hydrochloric acid solution by heterocyclic compounds containing a mercapto group," Corrosion Science, vol. 46, no. 12, pp. 3031-3040, 2004.

[41] M. A. Quraishi, M. Z. A. Rafiquee, S. Khan, and N. Saxena, "Corrosion inhibition of aluminium in acid solutions by some imidazoline derivatives," Journal of Applied Electrochemistry, vol. 37, no. 10, pp. 1153-1162, 2007.

[42] S. Caporali, A. Fossati, A. Lavacchi, I. Perissi, A. Tolstogouzov, and U. Bardi, "Aluminium electroplated from ionic liquids as protective coating against steel corrosion," Corrosion Science, vol. 50, no. 2, pp. 534-539, 2008.

[43] G. Yue, X. Lu, Y. Zhu, X. Zhang, and S. Zhang, "Surface morphology, crystal structure and orientation of aluminium coatings electrodeposited on mild steel in ionic liquid," Chemical Engineering Journal, vol. 147, no. 1, pp. 79-86, 2009.
[44] A. Inglese, P. D’Angelo, R. De Lisi, and S. Milioto, "Surface tension, heat capacity, and volume of amphiphilic compounds in formamide solutions," Journal of Solution Chemistry, vol. 27, no. 5, pp. 403-424, 1998.

[45] P. Zhao, C. Zhong, L. Hunag, L. Niu, and F. Zhang, "Corrosion inhibition of dibenzo $[1,4,8,11]$ tetraaza [14] annulene nickel on steel in $1 \mathrm{M} \mathrm{HCl}$," Corrosion Science, vol. 50, no. 8, pp. 2166-2171, 2008.

[46] N. Kimizuka and T. Nakashima, "Spontaneous self-assembly of glycolipid bilayer membranes in sugar-philic ionic liquids and formation of ionogels," Langmuir, vol. 17, no. 22, pp. 6759-6761, 2001.

[47] L. C. Branco, J. N. Rosa, J. J. Moura Ramos, and C. A. M. Afonso, "Preparation and characterization of new room temperature ionic liquids," Chemistry, vol. 8, no. 16, pp. 3671-3677, 2002.

[48] J. Pernak, K. Sobaszkiewicz, and J. Foksowicz-Flaczyk, "Ionic liquids with symmetrical dialkoxymethyl-substituted imidazolium cations," Chemistry, vol. 10, no. 14, pp. 34793485, 2004.

[49] Z. B. Zhou, H. Matsumoto, and K. Tatsumi, "Low-melting, low-viscous, hydrophobic ionic liquids: 1-Alkyl(alkyl ether)3- methylimidazolium perfluoroalkyltrifluoroborate," Chemis try, vol. 10, no. 24, pp. 6581-6591, 2004.

[50] Q. Liu, M. H. A. Janssen, F. Van Rantwijk, and R. A. Sheldon, "Room-temperature ionic liquids that dissolve carbohydrates in high concentrations," Green Chemistry, vol. 7, no. 1, pp. 39-42, 2005.

[51] W. A. Henderson, V. G. Young, D. M. Fox, H. C. De Long, and P. C. Trulove, "Alkyl vs. alkoxy chains on ionic liquid cations," Chemical Communications, no. 35, pp. 3708-3710, 2006.

[52] Z. Fei, W. H. Ang, D. Zhao et al., "Revisiting etherderivatized imidazolium-based ionic liquids," Journal of Physical Chemistry B, vol. 111, no. 34, pp. 10095-10108, 2007.

[53] J. Malyszko and M. Scendo, "Redox equilibria in the $\mathrm{Cu}^{2+}$ $\mathrm{Cu}^{+}-\mathrm{Cu}$ system in water-dimethylsulphoxide (DMSO) mixtures," Monatshefte für Chemie Chemical Monthly, vol. 118, no. 4, pp. 435-443, 1987.

[54] J. Matyszko and M. Scendo, "The stepwise reduction of $\mathrm{Cu}(\mathrm{II})$ at a platinum electrode in water $+N, N$-dimethylformamide mixtures," Journal of Electroanalytical Chemistry, vol. 269, no. 1, pp. 113-128, 1989.

[55] J. Małyszko and M. Scendo, "Electrode kinetics of the $\mathrm{Cu}(\mathrm{II}) / \mathrm{Cu}(\mathrm{I})$ system at platinum in water + dimethylsulphoxide (DMSO) mixtures," Journal of Electroanalytical Chemistry, vol. 250, no. 1, pp. 61-72, 1988.

[56] M. Scendo and J. Malyszko, "Influence of benzotriazole and tolyltriazole on the copper electrodeposition on polycrystalline platinum from acidic chloride solutions," Journal of the Electrochemical Society, vol. 147, no. 5, pp. 1758-1762, 2000.

[57] S. S. Abdel-Rehim, A. M. Magdy, and K. F. Khaled, "The inhibition of 4-( $2^{\prime}$-amino- $5^{\prime}$-methylphenylazo $)$ antipyrine on corrosion of mild steel in $\mathrm{HCl}$ solution," Materials Chemistry and Physics, vol. 70, no. 3, pp. 268-273, 2001.

[58] M. Elachouri, M. S. Hajji, M. Salem et al., "Some nonionic surfactants as inhibitors of the corrosion of iron in acid chloride solutions," Corrosion, vol. 52, no. 2, pp. 103-108, 1996.

[59] B. R. Babu and R. Holze, "Corrosion and hydrogen permeation inhibition for mild steel in $\mathrm{HCl}$ by isomers of organic compounds," British Corrosion Journal, vol. 35, no. 3, pp. 204-209, 2000.

[60] V. Shinde, S. R. Sainkar, and P. P. Patil, "Corrosion protective poly(o-toluidine) coatings on copper," Corrosion Science, vol. 47, no. 6, pp. 1352-1369, 2005. 
[61] D. W. Suggs and A. J. Bard, "Scanning tunneling microscopic study with atomic resolution of the dissolution of $\mathrm{Cu}(100)$ electrodes in aqueous chloride media," Journal of Physical Chemistry, vol. 99, no. 20, pp. 8349-8355, 1995.

[62] G. M. Brisard, E. Zenati, H. A. Gasteiger, N. M. Marković, and P. N. Ross, "Underpotential deposition of lead on $\mathrm{Cu}(100)$ in the presence of chloride: ex-situ low-energy electron diffraction, auger electron spectroscopy, and electrochemical studies," Langmuir, vol. 13, no. 8, pp. 2390-2397, 1997.

[63] G. Brisard, N. Bertrand, P. N. Ross, and N. M. Marković, "Oxygen reduction and hydrogen evolution-oxidation reactions on $\mathrm{Cu}(\mathrm{hkl})$ surfaces," Journal of Electroanalytical Chemistry, vol. 480, no. 1-2, pp. 219-224, 2000.

[64] H. Ma, S. Chen, B. Yin, S. Zhao, and X. Liu, "Impedance spectrospic study of corrosion inhibition of copper by surfactants in the acidic solutions," Corrosion Science, vol. 45, no. 5, pp. 867-882, 2003.

[65] D. Hang, L. Gao, G. Zhou, and K. Y. Lee, "Undecyl substitution in imidazole and its action on corrosion inhibition of copper in aerated acidic chloride media," Journal of Applied Electrochemistry, vol. 38, pp. 71-76, 2008.

[66] E. Yeager, "Electrocatalysts for $\mathrm{O}_{2}$ reduction," Electrochimica Acta, vol. 29, no. 11, pp. 1527-1537, 1984.

[67] D. Pletcher and S. Sotiropoulos, "A study of cathodic oxygen reduction at platinum using microelectrodes," Journal of Electroanalytical Chemistry, vol. 356, no. 1-2, pp. 109-119, 1993.

[68] A. H. Moreira, A. V. Benedetti, P. L. Cabot, and P. T. A. Sumodjo, "Electrochemical behaviour of copper electrode in concentrated sulfuric acid solutions," Electrochimica Acta, vol. 38, no. 7, pp. 981-987, 1993.

[69] H. P. Lee and K. Nobe, "Kinetics and mechanisms of $\mathrm{Cu}$ electrodissolution in chloride media," Journal of the Electrochemical Society, vol. 133, no. 10, pp. 2035-2043, 1986.

[70] F. K. Crundwell, "The anodic dissolution of copper in hydrochloric acid solutions," Electrochimica Acta, vol. 37, no. 15, pp. 2707-2714, 1992.

[71] E. A. Noor and A. H. Al-Moubaraki, "Thermodynamic study of metal corrosion and inhibitor adsorption processes in mild steel/1-methyl-4[2'(-X)-styryl pyridinium iodides/hydrochloric acid systems," Materials Chemistry and Physics, vol. 110, no. 1, pp. 145-154, 2008.

[72] V. R. Saliyan and A. V. Adhikari, "Quinolin-5-ylmethylene-3[8-(trifluoromethyl)quinolin-4-yl] thiopropanohydrazide as an effective inhibitor of mild steel corrosion in $\mathrm{HCl}$ solution," Corrosion Science, vol. 50, no. 1, pp. 55-61, 2008.

[73] S. S. Abd El Rehim, H. H. Hassan, and M. A. Amin, "Corrosion inhibition of aluminum by 1,1(lauryl amido)propyl ammonium chloride in $\mathrm{HCl}$ solution," Materials Chemistry and Physics, vol. 70, no. 1, pp. 64-72, 2001.

[74] S. T. Arb and K. M. Emran, "Thermodynamic study on corrosion inhibition of Fe78B13Si9 metallic glass alloy in $\mathrm{Na} 2 \mathrm{SO} 4$ solution at different temperatures," International Journal of Applied Chemistry, vol. 3, pp. 69-77, 2007.

[75] G. K. Gomma and M. H. Wahdan, "Schiff bases as corrosion inhibitors for aluminium in hydrochloric acid solution," Materials Chemistry \& Physics, vol. 39, no. 3, pp. 209-213, 1995.

[76] A. K. Maayta and N. A. F. Al-Rawashdeh, "Inhibition of acidic corrosion of pure aluminum by some organic compounds," Corrosion Science, vol. 46, no. 5, pp. 1129-1140, 2004.

[77] M. Lagrenée, B. Mernari, M. Bouanis, M. Traisnel, and F. Bentiss, "Study of the mechanism and inhibiting efficiency of 3,5-bis(4-methylthiophenyl)-4H-1,2,4-triazole on mild steel corrosion in acidic media," Corrosion Science, vol. 44, no. 3 , pp. 573-588, 2002.
[78] G. N. Mu, T. P. Zhao, M. Liu, and T. Gu, "Effect of metallic cations on corrosion inhibition of an anionic surfactant for mild steel," Corrosion, vol. 52, no. 11, pp. 853-856, 1996.

[79] F. Bentiss, M. Lagrenée, B. Elmehdi, B. Mernari, M. Traisnel, and H. Vezin, "Electrochemical and quantum chemical studies of 3,5-Di (n-Tolyl)-4-amino-1,2,4-triazole adsorption on mild steel in acidic media," Corrosion, vol. 58, no. 5, pp. 399-407, 2002.

[80] M. Şahin, S. Bilgiç, and H. Yilmaz, "The inhibition effects of some cyclic nitrogen compounds on the corrosion of the steel in $\mathrm{NaCl}$ mediums," Applied Surface Science, vol. 195, no. 1-4, pp. 1-7, 2002.

[81] X. Li, L. Tang, H. Liu, G. Mu, and G. Liu, "Influence of halide ions on inhibitive performance of cetyl trimethyl ammonium bromide in various concentrations of phosphoric acid for cold rolled steel," Materials Letters, vol. 62, no. 15, pp. 2321-2324, 2008.

[82] B. V. Savithri and S. M. Mayanna, "Tetrabutyl ammonium iodide, cetyl pyridinium bromide and cetyl trimethyl ammonium bromide as corrosion inhibitors for mild steel in sulphuric acid," Indian Journal of Chemical Technology, vol. 3, no. 5, pp. 256-258, 1996.

[83] F. Bensajjay, S. Alehyen, M. El Achouri, and S. Kertit, "Corrosion inhibition of steel by 1-phenyl 5-mercapto 1,2,3,4-tetrazole in acidic environments $\left(0.5 \mathrm{M} \mathrm{H}_{2} \mathrm{SO}_{4}\right.$ and 1/3 M HPO)," Anti-Corrosion Methods and Materials, vol. 50, no. 6, pp. 402-409, 2003.

[84] F. Bentiss, M. Lebrini, and M. Lagrenée, "Thermodynamic characterization of metal dissolution and inhibitor adsorption processes in mild steel/2,5-bis(n-thienyl)-1,3,4-thiadiazoles/ hydrochloric acid system," Corrosion Science, vol. 47, no. 12, pp. 2915-2931, 2005.

[85] W. H. Li, Q. He, S. T. Zhang, C. L. Pei, and B. R. Hou, "Some new triazole derivatives as inhibitors for mild steel corrosion in acidic medium," Journal of Applied Electrochemistry, vol. 38, no. 3, pp. 289-295, 2008.

[86] X. Li and G. Mu, "Tween-40 as corrosion inhibitor for cold rolled steel in sulphuric acid: weight loss study, electrochemical characterization, and AFM," Applied Surface Science, vol. 252, no. 5, pp. 1254-1265, 2005.

[87] M. Bouklah, B. Hammouti, M. Lagrenée, and F. Bentiss, "Thermodynamic properties of 2,5-bis(4-methoxyphenyl)1,3,4-oxadiazole as a corrosion inhibitor for mild steel in normal sulfuric acid medium," Corrosion Science, vol. 48, no. 9, pp. 2831-2842, 2006.

[88] M. Benabdellah, R. Touzani, A. Dafali, B. Hammouti, and S. El Kadiri, "Ruthenium-ligand complex, an efficient inhibitor of steel corrosion in $\mathrm{H}_{3} \mathrm{PO}_{4}$ media," Materials Letters, vol. 61, no. 4-5, pp. 1197-1204, 2007.

[89] X. Li, S. Deng, G. Mu, H. Fu, and F. Yang, "Inhibition effect of nonionic surfactant on the corrosion of cold rolled steel in hydrochloric acid," Corrosion Science, vol. 50, no. 2, pp. 420-430, 2008. 

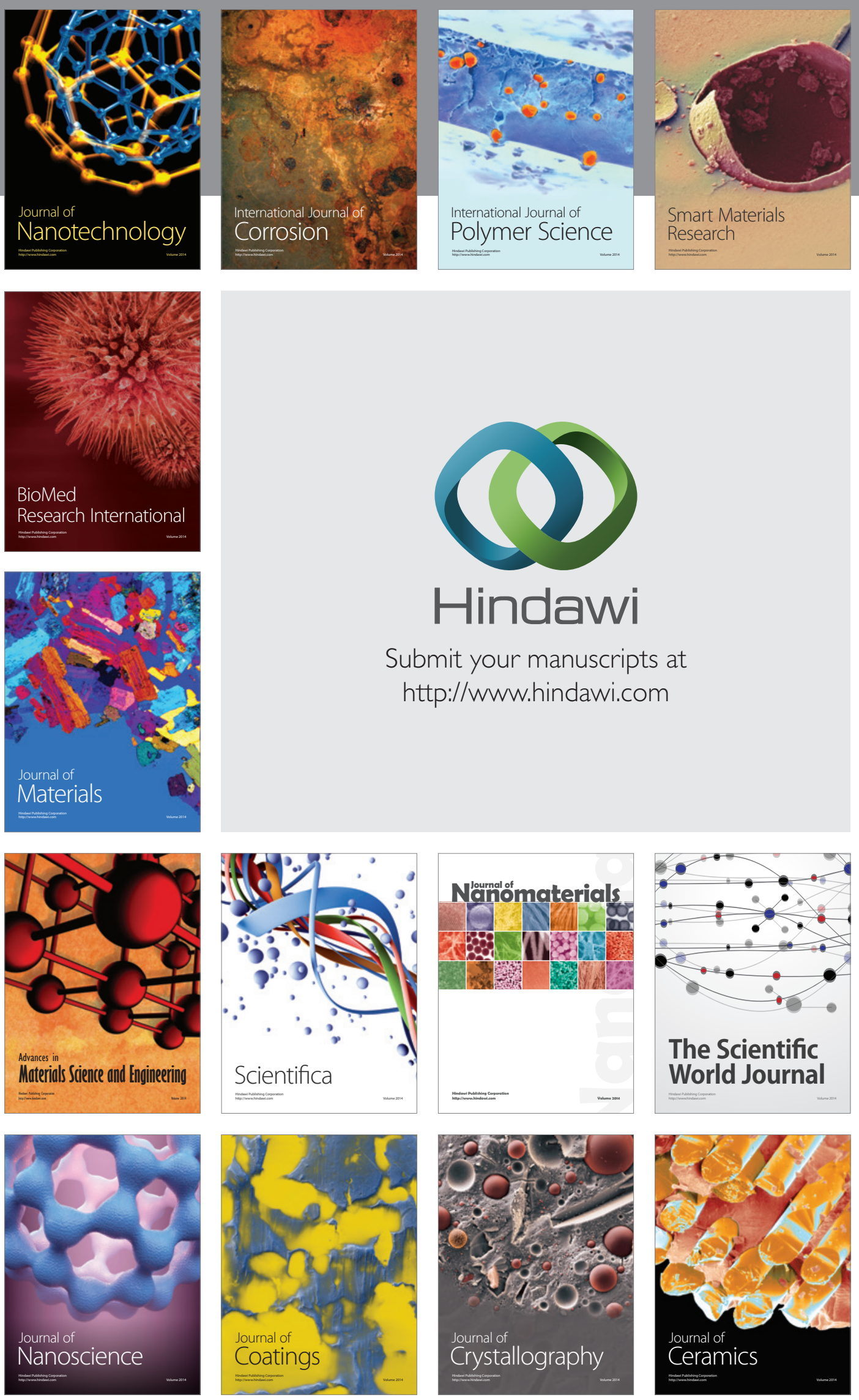

The Scientific World Journal

Submit your manuscripts at

http://www.hindawi.com

\section{World Journal}

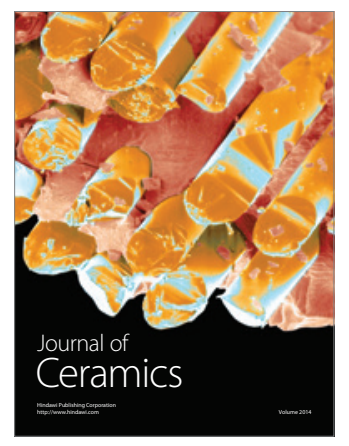

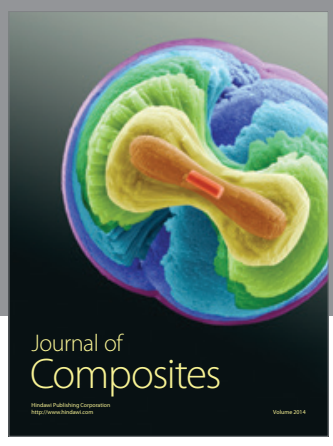
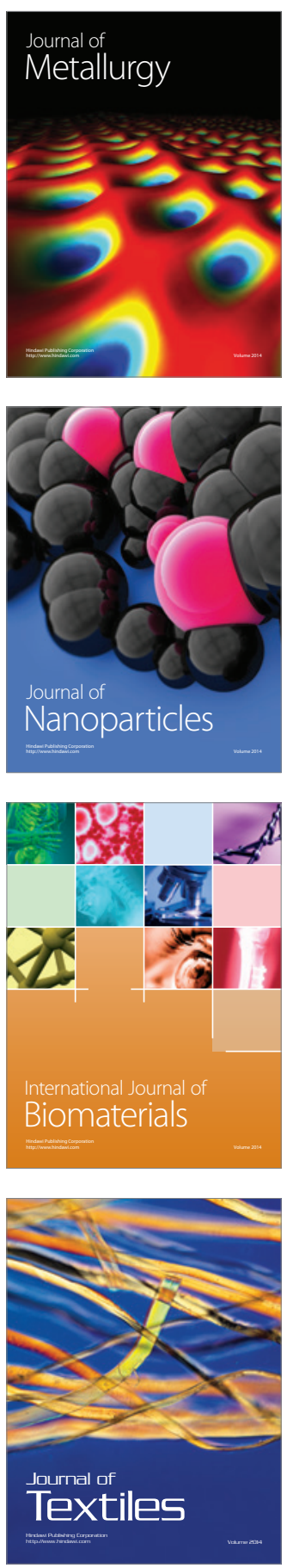